\title{
Portomesenteric venous thrombosis as a rare cause of acute abdomen in a young patient: What should be the process of diagnosis and management?
}

Mehmet İnan', Tansel Sarıoğlu², Tülay Hakkı Serhat ${ }^{2}$

ABSTRACT

'Department of General Surgery, Mağusa Medical Center, Gazimagusa, Turkish Republic of Northern Cyprus

2Department of Radiology, Mağusa Medical Center, Gazimagusa, Turkish Republic of Northern Cyprus

\section{Address for Correspondence} Dr. Mehmet İnan

Department of General Surgery, Mağusa Medical Center, Gazimagusa, Turkish Republic of Northern Cyprus Phone.: +903923665085 e-mail: inanmehmet@hotmail.com

Received: 10.01 .2012 Accepted: 03.04.2012 Online Available Date: 28.05.2013

OCopyright 2013 by Turkish Surgical Association

Available online at www.ulusalcerrahidergisi.org
This report aimed to discuss indications for radiological evaluation, laboratory investigation for thrombophilic risk factors, and the duration of anticoagulation therapy in porto-mesenteric venous thrombosis, based on a young patient who presented with acute abdomen and ascites. We investigated the acquired and genetic thrombophilic risk factors and the diagnostic process. Abdominal CT and Doppler US were found to be useful radiological tools in both diagnosis and follow-up of portomesenteric thrombosis. The investigated thrombophilic factors, PT G20210A, MTHFR C677T and MTHFR A1298C, were positive for heterozygous mutations and high levels of lupus anticoagulant and factor VIII were detected. Rapid ascites resolution and an improvement in abdominal pain after meals were observed following anticoagulation. Follow-up examination after six months showed that the portomesenteric thrombosis had completely resolved. Evaluation by CT is recommended for patients with acute abdomen and ascites, especially if ultrasonography failed to show any specific pathology. Several acquired or genetic thrombophilic factors were identified in a patient in whom local precipitating factors were absent. For patients with genetic thrombophilic risk factors and thrombosis at an uncommon site in the body, lifelong treatment with anticoagulants is recommended.

Key Words: Portomesenteric venous thrombosis, anticoagulation, acute abdomen

\section{INTRODUCTION}

Portomesenteric venous thrombosis is an uncommon disease, difficult to diagnose and leading to mortality. Clinical suspicion is crucial in diagnosis (1-3). Congenital or acquired prothrombotic disorders, other thrombophilic factors or local factors play a role in etiology. Typically, a combination of multiple factors is detected (4). Abdominal Doppler ultrasonography (U.S.) for portal venous thrombosis and portal venous phase of contrast-enhanced tomography (CT) for mesenteric thrombosis are valuable methods for accurate diagnosis and follow-up (5). A case is discussed below, who presented with right lower quadrant pain and free fluid and incidentally diagnosed with portomesenteric thrombosis, in terms of diagnosis, screening of thrombophilic risk factors and duration of treatment.

\section{CASE PRESENTATION}

A 24-year-old woman presented to our clinics with persistent abdominal pain. She was evaluated on the previous day at another clinic with similar complaints, her laboratory tests and abdominal US did not reveal any pathologies and the patient departed from that clinic on her request. Her pain increased overnight and she developed nausea and vomiting following oral intake.

On physical examination, bowel sounds were decreased and the right lower quadrant was tender. She was tachycardic $100 / \mathrm{min}$ heart rate with an arterial blood pressure of $110 / 80 \mathrm{mmHg}$. On U.S. free fluid was detected in the right lower quadrant, right paracolic area and in the pouch of Douglas, the terminal ileal wall was thickened (edema), and bowel loops with decreased peristaltism in the right hypogastrium. A plain abdominal X-ray showed air-fluid levels in the right lower quadrant. The leukocyte count was 8.900/UL, hemoglobin value was $12 \mathrm{~g} / \mathrm{dL}$ and platelet count was 265.000/UL. Amylase, AST and ALT values were within normal limits. The patient was hospitalized. During the next 24 hours of follow-up, she had episodes of pain relief, although oral intake exacerbated her pain. Due to the localization of pain to the right lower quadrant and leukocyte count increasing up to $11.000 / \mathrm{mL}$, she was planned for laparotomy with a presumptive diagnosis of acute appendicitis. The abdomen was explored through a Mc Burney incision, and serous free fluid was detected. The ileal segment, $60 \mathrm{~cm}$ in length from the terminal ileum, was found to be edematous. The appendix was edematous but was not infected. An appendectomy was performed, the abdomen was further explored but no other pathology was detected. 


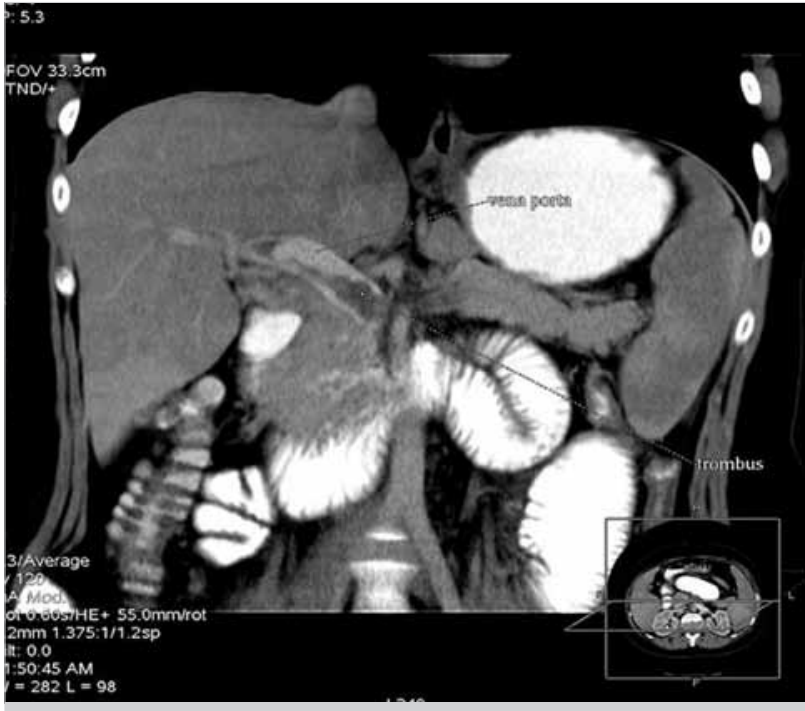

Figure 1. Abdominal CT: Portal venous thrombosis

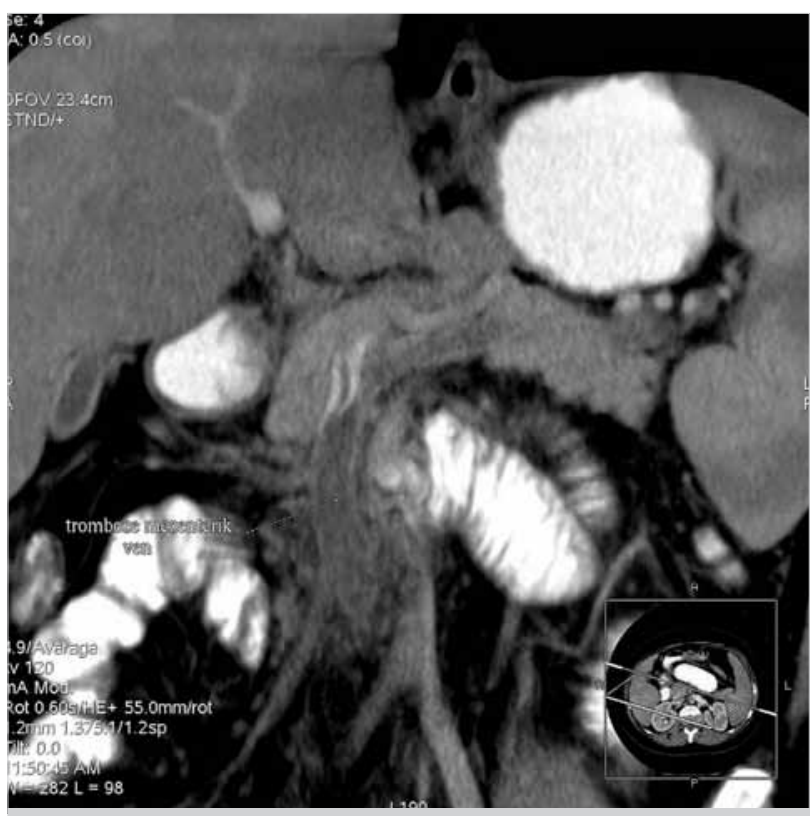

Figure 2. Abdominal CT: Mesenteric vein thrombosis

A suction drain was placed to the appendectomy site and the operation was terminated. The early postoperative period was uneventful. There was $400 \mathrm{cc}$. daily drainage of serous fluid, so the drain was kept in place. Pathological examination of the appendectomy material showed reactive hyperplastic changes in the appendix vermiformis.

Due to the persistence of abdominal ascites, she was started on colchicine for a probable Familial Mediterranean Fever induced serositis. The amount of drainage did not decrease after colchicine treatment. She was discharged with the drain, and scheduled for out-patient follow up. The amount of drainage did not show a significant decrease. On the $15^{\text {th }}$ postoperative day, she was re-admitted with complaint of abdominal pain after meals. A plain abdominal X-ray showed one small bowel loop with air-fluid level. The leukocyte count was 8.100/UL. An abdominal CT scan was obtained. The $\mathrm{CT}$ revealed thrombosis in the portal vein, splenic vein, mesenteric confluence, and superior mesenteric vein, heterogeneous patchy contrast enhancement in hepatic and splenic parenchyma, generalized edema in colon segments, and multiple mesenteric lymph nodes (Figure 1,2). The patient was started on fraxiparine $2 \times 0.6$ units and warfarin $5 \mathrm{mg} /$ day with a diagnosis of portomesenteric venous thrombosis. On the second day of this treatment, abdominal ascites disappeared and the surgical drain was removed.

The patient has been receiving warfarin treatment for the last 8 months, with dosage modifications to keep the INR value between 2-2.5. In addition, she was started on folic acid and vitamin B complex. During the last 8 months, she lost weight from her preoperative weight of 90 kilograms (BMI $33 \mathrm{~kg} / \mathrm{m}^{2}$ ) down to 65 kilograms (BMI $23.9 \mathrm{~kg} / \mathrm{m}^{2}$ ).

Genetic disorders that result in thrombosis were suspected in etiology in our patient who experienced venous thrombosis at a young age. Factor 8 level was determined as $385.1 \%$ (Normal range: 40-150). In the patient's family history, it was determined that a distant relative had several miscarriages, and used low molecular weight heparin during pregnancy, a history of thrombosis was not present in any other family members. A third month follow up Doppler U.S showed persistent thrombus in the portal system, but the sixth month Doppler U.S. revealed patent portal vein, mesenteric junction, splenic vein and superior mesenteric veins with no signs of thrombosis. The patient is still on warfarin therapy. Despite occasional cramp-like abdominal pain, she did not develop any further acute pathology. These pain episodes responded well to intramuscular diclofenac sodium.

\section{DISCUSSION}

Portomesenteric venous thrombosis is a rare disease. It can be seen in 2.7 out of 100 thousand people, with a mortality rate of $20-50 \%(1-3)$. There may often be delays in diagnosis and treatment because of variability of signs and symptoms. In general, venous thrombi result from a combination of multiple factors (4). Advanced age, intra-abdominal infections, cancer, cirrhosis, a history of using oral contraceptives, splenectomy, and previous upper abdominal surgery such as gastrectomy are among local or general thrombophilic factors (5). Portomesenteric thrombosis is often neglected as part of the differential diagnosis in patients with acute abdomen who do not have the previously mentioned factors. Only $40 \%$ of patients with portal vein thrombus have local factors, therefore in half of the patients any local factor that triggers thrombosis will not be found. In these patients, deficiency of antithrombin III, protein $\mathrm{C}$ and $\mathrm{S}$, hereditary mutations of Factor $\mathrm{V}$ Laden, ProthrombinG20210A, MTHFR C677T, MTHFR A1298C, or acquired thrombophilic disorders like primary myeloproliferative diseases, antiphospholipid syndrome, or paroxysmal nocturnal hemoglobinuria play a role (6).

Ascites is found in $60 \%$ of patients with portomesenteric thrombosis (7). Therefore, in patients with significant increases of abdominal pain in the post-prandial period, detection of ascites with clinical examination or ultrasonography portomesenteric thrombosis should be considered even if they are young. 
In our patient a diagnosis of appendicitis was made based on the findings that the pain was localized to the right, leukocyte counts raised during follow-up, sonography findings such as free fluid in the pericecal area and an appendectomy was performed. On abdominal exploration ascites and edema in the distal ileum were determined, but bowel wall congestion or ischemia-induced color change was not observed. The appendix was edematous but was not inflamed, so the abdomen was thoroughly explored, but no other pathologies were found. In cases where clinically acute appendicitis is suspected yet unsupported by US the selectivity of US is reported as $61.5 \%$. In such patients, preoperative abdominal CT may be useful in diagnosis (8). The portal venous phase of CT in conjunction with Doppler U.S. is a valuable diagnostic method in diagnosing portomesenteric thrombosis that provides the ability of early detection (9). Early diagnosis can avoid bowel gangrene, perforation and peritonitis findings, it can reduce the need for early or late laparotomy in $67 \%$ patients (7).

In this case, the patient was incidentally diagnosed with abdominal CT scan, which was performed due to persistent complaints. The absence of bowel gangrene requiring resection is thought to result from a possible partial occlusion and is formation of venous collaterals (10). Although the patient was operated for a diagnosis of acute appendicitis, this was not supported either clinically or pathologically. An intra-abdominal infection such as appendicitis or the presence of previous surgery was not accepted as possible causes of portomesenteric venous thrombosis. A prothrombotic disease was suspected as the underlying cause of this disease. The patient's thrombophilic risk factors were evaluated at Erciyes Medical Faculty five months after surgery. Factor $\mathrm{V}$ (Laden) mutation was not detected, heterozygous mutations of Prothrombin G20210A, MTHFR C677T, MTHFR A1298Cwere found in all three. Additionally, Protein $C$ and Protein $S$ levels were lower than normal, and lupus anticoagulant and Factor 8 levels were higher than normal. The low levels of Protein $C$ and Protein $S$ were not taken in to consideration since the patient was receiving warfarin treatment, still the increased level of lupus anticoagulant is significant for antiphospholipid syndrome. Factor VIII level was also found to be increased.

Laboratory screening for thrombophilia is important in individuals at high risk of thrombosis and in those who will benefit from anticoagulant therapy. Particularly in unprovoked thrombosis (without the involvement of local factors), the laboratory detection rate of factors that increase the risk of venous thrombosis is higher than $50 \%$. That is why laboratory-screening tests are recommended in young patients with unprovoked thrombosis, as in the presented case, with unexpected thrombosis localization $(11,12)$. Although detection rate of multifactorial prothrombotic genetic diseases is high in unprovoked thrombosis, there are also studies that reveal no benefit from these tests in either the treatment of acute illness or the prevention of recurrence risk $(13,14)$. In addition, there is not yet any controlled randomized study showing that laboratory screening for thrombophilia is useful in terms of venous thromboembolism risk (15). Some authors advocate abandoning routine laboratory screening for thrombophilia based on these reasons (16).
Heterozygous or homozygous MTHFR C677T mutation alone is reported as a low risk factor in terms of venous thrombosis, however when combined with prothrombin G20210A mutation, thrombosis risk increases (17). In the case described herein, PT G2021OA, MTHFR C677T and MTHFRA1298C mutations, the presence of antiphospholipid syndrome and high levels of factor VIII combined together shows an increased risk of thrombosis (18-20).

Oral anticoagulant therapy in patients with hereditary thrombophilia should be planned to keep the INR in the range of 2-2.5 at least for 6 months. Whereas spontaneous recanalization rate is low, complete or near complete recanalization rates are approximately $80 \%$ with anticoagulant therapy (7). Anticoagulant therapy should continue for life in patients with; multiple thrombophilic genetic mutations, cerebral or visceral and recurrent thrombosis, homozygous factor V Laden mutations, antithrombin deficiency, and carrying antiphospholipid antibodies $(11,12,18)$. In our case, the presence of visceral thrombosis and co-existence of multiple thrombophilic genetic mutations, even though heterozygous, shows that lifelong oral anticoagulation is essential, despite an annual $3 \%$ risk of serious bleeding (21). In this type of unprovoked (without local factors)venous thrombosis with thrombophilic genetic mutations, the risk of recurrence is reported to be higher than $25 \%$, while the mortality rate in recurrent thrombosis is approximately $5-12 \%(22,23)$.

\section{CONCLUSION}

In patients who present with right lower quadrant pain and ultrasonography does not reveal signs of acute appendicitis, should be further evaluated by preoperative CT especially if they also have ascites. Abdominal CT and Doppler US are helpful in the diagnosis and monitoring of portomesenteric thrombosis. Our patient with portomesenteric thrombosis had no local or general thrombophilic factors and was found to carry multiple genetic or acquired thrombophilia factors by laboratory tests. In such patients, lifelong anticoagulation therapy is recommended.

Informed Consent: Written informed consent was obtained from patients who participated in this case report.

Peer-review: Externally peer-reviewed.

Author Contributions: Concept - M.i.; Design - M.I.; Data Collection and/ or Processing - M.I.., T.S., H.S.T.; Analysis and/or Interpretation - M.I.., T.S., H.S.T.; Writer - M.I.

Conflict of Interest: No conflict of interest was declared by the authors.

Financial Disclosure: The authors declared that this study has received no financial support.

\section{REFERENCES}

1. Acosta S, Alhadad A, Svensson P, Ekberg O. Epidemiology, risk and prognostic factors in mesenteric venous thrombosis. $\mathrm{Br} J$ Surg 2008; 95: 1245-1251. [CrossRef]

2. Abdu RA, Zakhour BJ, Dallis DJ. Mesenteric venous thrombosis--1911 to 1984 . Surgery $1987 ; 101: 383-388$. 
3. Rhee RY, Gloviczki P, Mendonca CT, Petterson TM, Serry RD, Sarr $M G$, et al. Mesenteric venous thrombosis: still a lethal disease in the 1990s. J Vasc Surg 1994; 20: 688-697. [CrossRef]

4. Rosendaal FR. Venous thrombosis: a multicausal disease. Lancet 1999; 353: 1167-1173. [CrossRef]

5. Sacerdoti D, Serianni G, Gaiani S, Bolognesi M, Bombonato G, Gatta A. Thrombosis of the portal venous system. Journal of Ultrasound 2007; 10: 12-21. [CrossRef]

6. Valla DC, Condat B. Portal vein thrombosis in adults: pathophysiology, pathogenesis and management. J Hepatol 2000; 32: 865-871. [CrossRef]

7. Joh JH, Kim DI. Mesenteric and portal vein thrombosis: treated with early initiation of anticoagulation. Eur J Vasc Endovasc Surg 2005; 29: 204-208. [CrossRef]

8. İnan $\mathrm{M}$, Tulay $\mathrm{SH}$, Besim H, Karakaya J. The role of ultrasonography in acutre appendicitis and its comparison to Alvarado score. Ulusal Cerrahi Dergisi 2011; 27: 149-153.

9. Bradbury MS, Kavanagh PV, Bechtold RE, Chen MY, Ott DJ, Regan $J D$, et al. Mesenteric venous thrombosis: diagnosis and noninvasive imaging. Radiographics 2002; 22: 527-541. [CrossRef]

10. Ohnishi K, Okuda K, Ohtsuki T, Nakayama T, Hiyama Y, Iwama S, et al. Formation of hilar collaterals or cavernous transformation after portal vein obstruction by hepatocellular carcinoma. Observations in ten patients. Gastroenterology 1984; 87: 1150-1153.

11. Seligsohn U, Lubetsky A. Genetic susceptibility to venous thrombosis. N Engl J Med 2001; 344: 1222-1231. [CrossRef]

12. Liem TK, DeLoughery TG. First episode and recurrent venous thromboembolism: who is identifiably at risk? Semin Vasc Surg 2008; 21: 132-138. [CrossRef]

13. Baglin T, Luddington R, Brown K, Baglin C. Incidence of recurrent venous thromboembolism in relation to clinical and thrombophilic risk factors: prospective cohort study. Lancet 2003; 362: 523-526. [CrossRef]
14. Kearon C, Julian JA, Kovacs MJ, Anderson DR, Wells P, Mackinnon $B$, et al. Influence of thrombophilia on risk of recurrent venous thromboembolism while on warfarin: results from a randomized trial. Blood 2008; 112: 4432-4436. [CrossRef]

15. Cohn D, Vansenne F, Borgie C, Middledrop S. Thrombofilia testing for prevention of recurrent venous thromboembolism. Cochrane Database Syst Rev 2009; 1: CD007069.

16. Kyrle PA, Rosendaal FR, Eichinger S. Risk assessment for recurrent venous thrombosis. Lancet 2010; 376: 2032-2039. [CrossRef]

17. Ray JG, Shmorgun D, Chan WS. Common C677T polymorphism of the methylenetetrahydrofolate reductase gene and the risk of venous thromboembolism: meta-analysis of 31 studies. Pathophysiol Haemost Thromb 2002; 32: 51-58. [CrossRef]

18. Yirmibeşoğlu $M$, Vitoja Sidita, Çalık E, Terzi C. Superior mesenteric vein thrombosis due to Protrombin $20210 \mathrm{G} / \mathrm{A}$ and MTHFR C677T mutations: A case report. Ulusal Cerrahi Dergisi 2011; 27: 111-114.

19. Ozmen F, Ozmen MM, Ozalp N, Akar N. The prevalence of factor V (G1691A), MTHFR (C677T) and PT (G20210A) gene mutations in arterial thrombosis. Ulus Travma Acil Cerrahi Derg 2009; 15: 113-119.

20. Bobrow S. Excess factor VIII: A common cause of Hypercoagulability. J Am Board Fam Pract 2005; 18: 147-149. [CrossRef]

21. Linkins LA, Choi PT, and Douketis JD. Clinical impact of bleeding in patients taking oral anticoagulant therapy for venous thromboembolism. Ann Intern Med 2003; 139: 893-900. [CrossRef]

22. Eischer L, Eichinger S, Kyrle PA. Age at first venous thromboembolism and risk of recurrence: a prospective cohort study. Medicine (Baltimore) 2009; 88: 366-370. [CrossRef]

23. Naess IA, Christiansen SC, Romundstad P, Cannegieter SC, Hammerstrom J. Incidence and mortality of venous thromboembolism: a population-based study. J Thromb Haemost 2007; 5: 692-699. [CrossRef] 